\title{
Proposta de material pedagógico adaptado para o ensino remoto de gramática por meio de metodologias ativas na rede pública
}

\author{
Pedagogical Proposals for Adapted Remote Grammar Teaching Material through \\ Active Methodologies in Public Education
}

Ana Paula Prado Gomes, Maria Luiza Capuano Villar, Ana Cláudia Maynardes

ensino remoto, metodologia ativa, ensino público, gramática, gamificação

O artigo apresenta pesquisa e desenvolvimento de um material didático para prática pedagógica para o ensino da gramática da língua portuguesa na modalidade de ensino remoto, usando como base a metodologia Abordagem de Aprendizagem Linguística Ativa, empregada pelo projeto Gramaticoteca. Para tanto, foram utilizadas ferramentas de metodologia de design trabalhadas em modo remoto, bem como a participação direta dos professores participantes da Gramaticoteca. Como resultado, três materiais didáticos que têm como objetivo propor atividades síncronas e assíncronas que motivem a participação dos estudantes no aprendizado da gramática da língua portuguesa.

remote teaching, active methodology, public school, grammar, gamification

This article presents the research and development of didactic materials for pedagogical practice on the remote teaching of portuguese grammar, based on the Active Linguistic Learning Approach, project Gramaticoteca's currently applied methodology. For such, we used all applied online design methodologies tools, as well as the direct participation of teachers from Gramaticoteca. The results: didactic materials and dynamics that propose synchronous and asynchronous activities that inspire student participation in the learning of portuguese grammar.

\section{Introdução}

Com a pandemia do Covid-19 que assolou o mundo em 2020, a educação foi forçada a passar por uma reformulação temporária em prol da saúde pública, configurando uma mudança no modelo de ensino presencial para o Ensino Remoto. O Ensino Remoto (ER), além de apresentar suas próprias inconstâncias, dificulta a aplicação de determinadas metodologias ativas nas aulas.

Devido a isso, os professores que lecionam dentro da Gramaticoteca, um projeto ativo desde 2017 fundamentado na abordagem da aprendizagem linguística ativa, de Eloisa Pilati, encontraram dificuldades para adaptar suas aulas para o ER, tais como: a falta de engajamento e falta de interesse dos alunos devido à facilidade de distração; e o desafio da confecção do material pedagógico concreto, que antes era feito em conjunto nas salas de aula.

Com essas dificuldades em mente, a professora Ana Carolina de Castro, que aplica a Gramaticoteca para alunos de $2^{\circ}$ e $3^{\circ}$ ano do Centro de Ensino Médio Elefante Branco

Anais do $10^{\circ} \mathrm{CIDI}$ e $10^{\circ} \mathrm{CONGIC}$

Kelli C.A.S. Smythe, Rafael de Castro Andrade (orgs.)

Sociedade Brasileira de Design da Informação - SBDI

Curitiba | Brasil | 2021
Proceedings of the $10^{\text {th }} \mathrm{CIDI}$ and $10^{\text {th }} \mathrm{CONGIC}$

Kelli C.A.S. Smythe, Rafael de Castro Andrade (orgs.)

Sociedade Brasileira de Design da Informação - SBDI Curitiba | Brazil | 2021 
(CEMEB), se aliou ao departamento de Design da Universidade de Brasília (UnB) para procurar soluções. Assim, o presente trabalho tem como objetivo propor materiais adaptados ao ensino remoto alinhados à metodologia de ensino aplicada na Gramaticoteca que dialoguem com teorias da gamificação, para promover a participação dos alunos durante as aulas.

A partir de pesquisas de campo, entrevistas com docentes do projeto e análise de similares, foram definidos alguns requisitos quanto a confecção e conceitualização do material, levando em consideração o contexto da pandemia, as inconsistências do ER e as condições financeiras diversas dos alunos e professores. No total, foram desenvolvidos três materiais que abordam conteúdos diferentes, assim como sugestões de dinâmicas a serem aplicadas em conjunto com o material.

\section{Fundamentação teórica}

\section{A Gramaticoteca}

A metodologia de ensino aplicada na Gramaticoteca, publicada em Linguística, Gramática e Aprendizagem Ativa (Pilati, 2017), concilia três dimensões do processo de ensino e aprendizagem, sendo elas as dimensões: Linguística, Aprendizagem e Práticas Ativas. A proposta de Pilati tem como objetivo conscientizar os estudantes de que todo mundo possui um conhecimento inato da língua materna a partir do uso de práticas ativas no ensino.

Desse modo, a participação ativa do estudante no processo de aprendizagem é essencial em sua metodologia.

Em sua abordagem, Pilati (2017) propõe o uso de materiais concretos em sala de aula como forma de extrair as estruturas gramaticais internalizadas e trazê-las para um contexto formal, para que os estudantes sejam capazes de aplicar esse conhecimento na construção de textos e em provas e vestibulares. Em relação aos materiais concretos, Pilati (2017, p. 109) diz: "O material concreto promove a compreensão dos fenômenos gramaticais e a aprendizagem ativa, despertando a consciência acerca da estrutura sintática da língua e dos fenômenos gramaticais".

\section{Gamificação}

A gamificação pode ser definida como o uso de elementos de jogo em atividade de não jogo, de acordo com Deterding et al. (2011). Sua aplicação na educação implica em processos de ensino mais engajadores e que instigam a motivação intrínseca do aluno a aprender, além de promover a interação entre os alunos

É possível observar alguns elementos da gamificação sendo usados na gramaticoteca, como o uso de recompensas e a aplicação de atividades competitivas e cooperativas para incentivar a participação dos alunos. Esses mecanismos foram incorporados nas dinâmicas propostas para cada material concreto, levando também em consideração o princípio da calibragem cuidadosa, para que as dinâmicas não se tornem nem frustrantes nem entediantes. 


\section{Design e Educação}

Por ter que lidar com as particularidades de aprendizado de cada aluno, os professores são incentivados a explorar novas técnicas e metodologias para que o conteúdo possa ser entendido de forma clara. Com a escolha de trabalhar com materiais pedagógicos concretos, essa dinâmica fica ainda mais visível, uma vez que o conteúdo ministrado em aula também é expressado por cores, formas e encaixes, permeando o campo de design. A partir da manipulação de ferramentas e materiais diversos, o aluno planeja, pesquisa, seleciona, experimenta e vai construindo seu próprio protótipo.

A contribuição do designer, portanto, vem a partir da aplicação de seus conhecimentos técnicos no desenvolvimento de materiais pedagógicos para que os educadores tenham novas possibilidades de ensino que explorem sua capacidade máxima de transmitir a informação (Coutinho \& Lopes, 2011).

\section{Metodologia}

O desenvolvimento do projeto seguiu o caminho de contextualização, pesquisa, conceitualização, prototipação e está atualmente em fase de testes. Durante a fase de contextualização, foram realizados encontros virtuais com docentes participantes da Gramaticoteca. Essa fase ocorreu simultaneamente com a fase de pesquisa, em que foram realizadas pesquisas bibliográficas, análise de similares, entrevistas e pesquisas. As pesquisas de campo foram realizadas pela observação do decorrer de duas aulas virtuais da gramaticoteca, ministradas para turmas dos $2^{\circ}$ e $3^{\circ}$ anos do CEMEB de Brasília.

Foi utilizada a metodologia do Double Diamond (Duplo Diamante) com contribuições do Design Thinking. Na fase de divergência, partindo do tema central de "Ensino Remoto" houve a expansão do escopo por meio de brainstorms e entrevistas com os docentes, aliando as necessidades da Gramaticoteca à modalidade de ensino online. O projeto teve como prérequisitos: ser um material pedagógico concreto, passível de ser replicável com coisas que os alunos tivessem em casa, ter baixo custo e que sua confecção pudesse ser feita em aula. Portanto, na fase de convergência, optou-se pelo uso de sucatas e materiais recicláveis, como papelão, papel, entre outros de fácil manipulação e acesso.

As fases de desenvolvimento e prototipação ocorreram posteriormente. $O$ design dos materiais pedagógicos foram conceitualizados em conjunto com as dinâmicas, e em seguida foram realizados testes para definir os melhores suportes, formas e mecanismos da gamificação. Os protótipos foram concebidos com a finalidade de transmitir o conteúdo estudado em aula de forma mais criativa, livre e com o intuito de facilitar a visualização e entendimento dos fenômenos gramaticais por parte do aluno. 


\section{Propostas}

Como resultado do trabalho, foram projetados três materiais pedagógicos que se adaptam tanto ao modo remoto quanto ao modo presencial, síncrono e assíncrono. Esses artefatos consistem em materiais concretos que carregam em sua concepção o conteúdo abordado de forma a externalizar o conhecimento e o processo de compreensão da matéria, juntamente com propostas de dinâmicas gamificadas para serem realizadas tendo o material concreto como base. Eles não seriam trabalhados como um modelo a ser seguido à risca, e sim como uma inspiração para instigar a criatividade do aluno no ato do fazer, sem impor limitação de insumos ou ferramentas.

\section{Materiais concretos}

O primeiro material, Pareando, aborda o conteúdo "termos da oração". O educador se encontra livre para definir com quais termos deseja trabalhar. Nesse material, confeccionado junto à professora Ana Carolina de Castro, os termos trabalhados são: sujeito, verbo, objeto e complemento.

O material consiste em 16 cartas, sendo 8 delas cartas fixas, que correspondem a um termo (Ex: sujeito) e 8 cartas variáveis, que correspondem a palavras ou expressões definidas pelo educador, que devem formar pares com as cartas fixas. Essa configuração das cartas tem como objetivo evidenciar que as palavras não possuem, intrinsecamente, a função de sujeito ou objeto, etc. Elas exercem essas funções de acordo com o contexto em que se encontram, e cabe ao aluno encontrar essas relações a partir de dinâmicas realizadas em grupo. 
Figura 1: Exemplo de como as cartas variáveis podem exercer mais de uma função
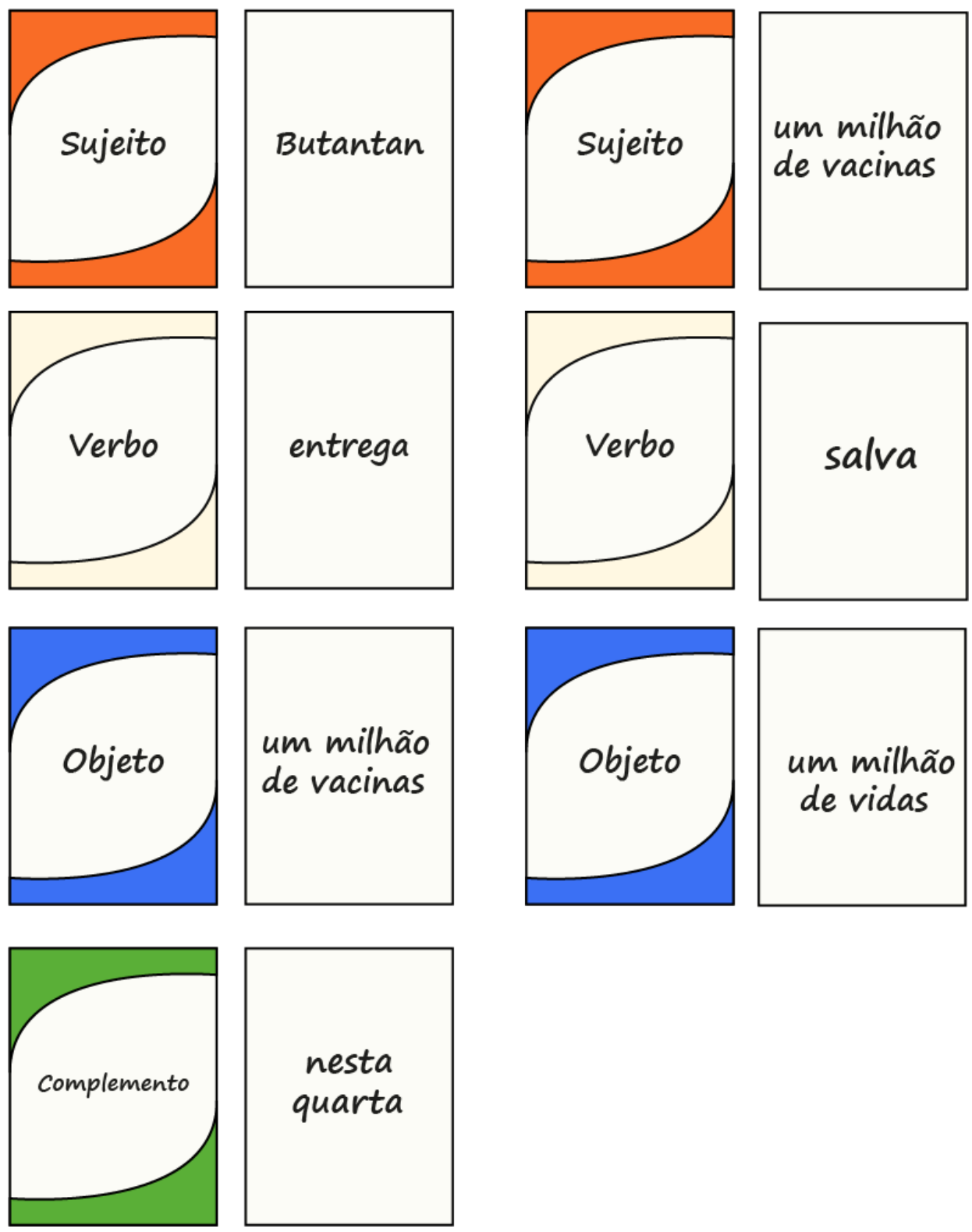
Figura 2: Protótipo do Pareando



O segundo material, Encaixes Sintáticos, trabalha o uso da vírgula. Esse artefato adiciona outra camada de sentido no conteúdo de termos da oração, que é a relação que os termos têm entre si em uma sentença, colocando a estrutura da ordem direta em foco, dialogando com a citação de Pilati (2017). O uso da vírgula vem como um mecanismo da escrita para quebrar a ordem direta, sem entrar em detalhes profundos de regras. O funcionamento dessas relações e desse mecanismo é reproduzido em nosso material por meio dos encaixes, como representado a seguir:

Figura 3: Protótipo do Encaixes Sintáticos em papelão e papel colorido

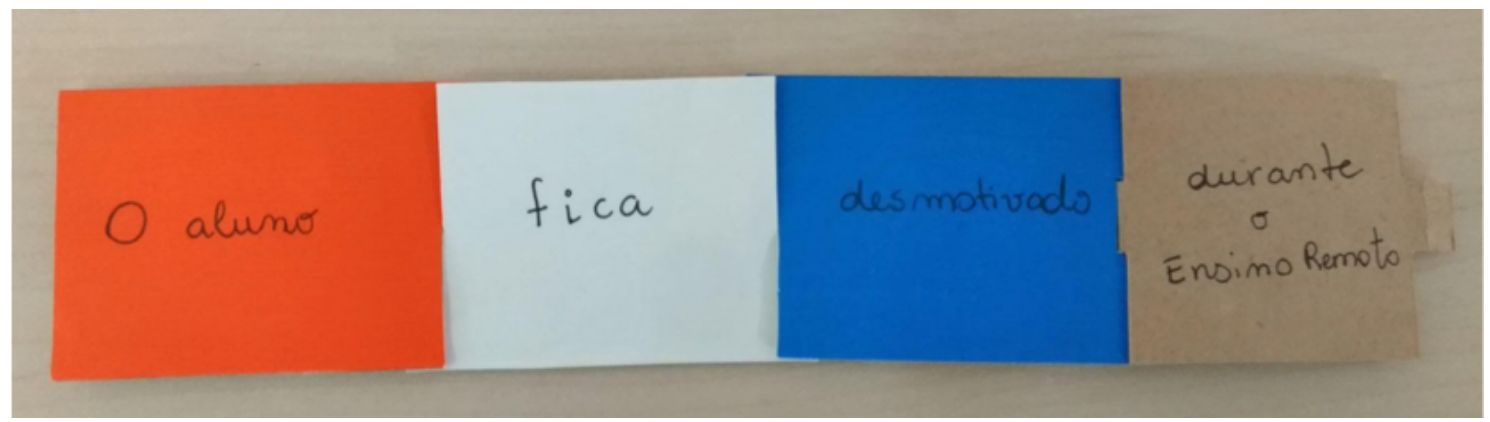


Figura 4: Protótipo com o complemento deslocado

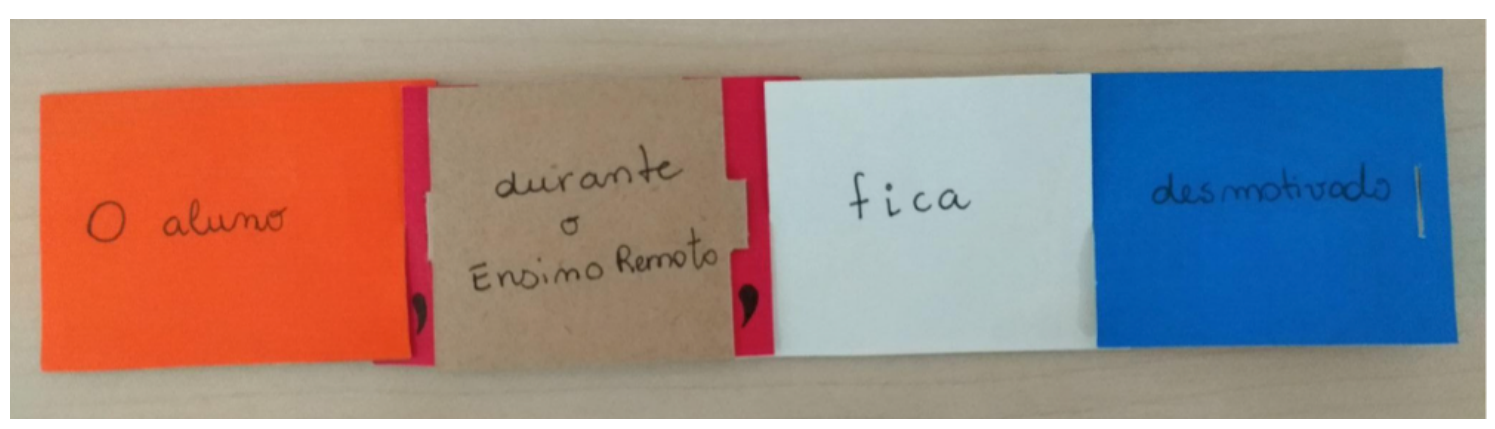

Figura 5: Possíveis encaixes e configurações de oração

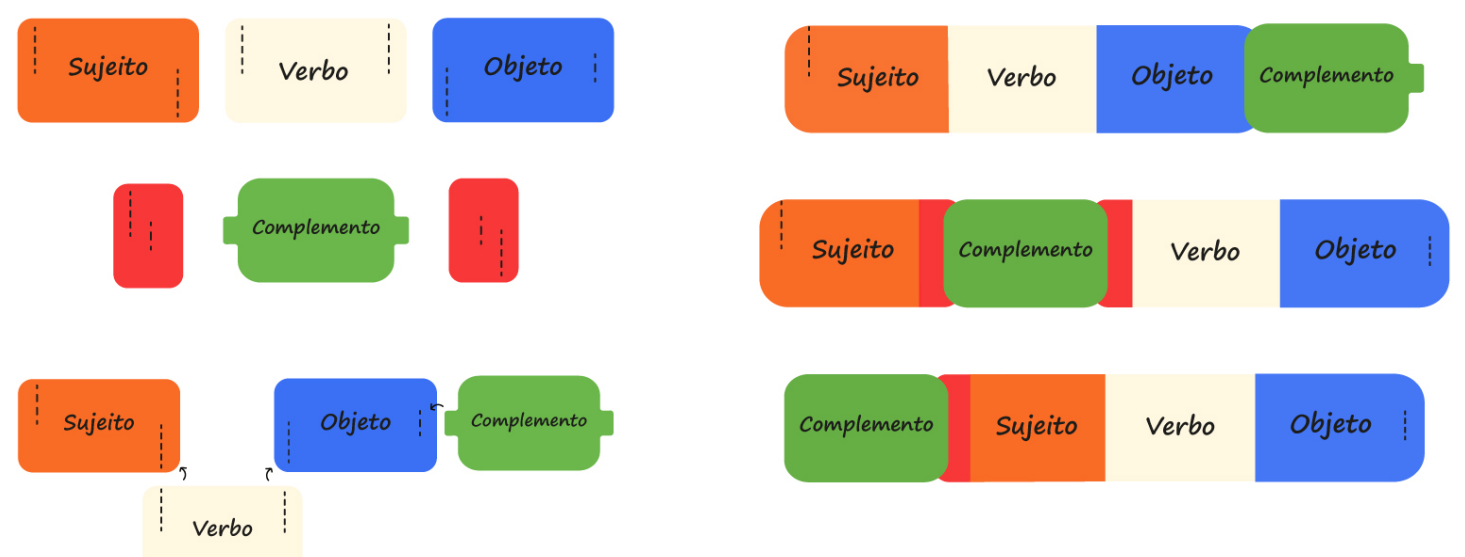

O terceiro material, Gira-Gira, trabalha a transitividade verbal e seleção argumental. Partindo do princípio dos termos da oração, estudado anteriormente, esse artefato propõe a visualização clara do que seria transitividade, explicando o conceito de que "o verbo pede um complemento específico". O artefato é uma representação visual da estrutura dos termos como objeto íntegro, em que o verbo não se sustenta sozinho. 
A. P. P. Gomes, M. L. C. Villar, \& A. C. Maynardes|Proposta de material pedagógico adaptado para o ensino remoto de gramática por meio de metodologias ativas na rede pública

Figura 6: Protótipo do Gira-Gira em caixa de leite e papel colorido

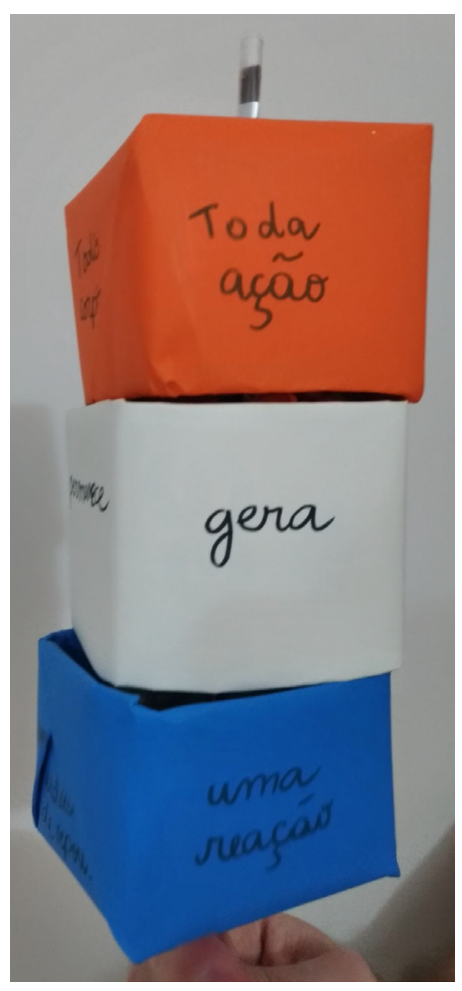

Figura 7: A visualização da seleção argumental pela manipulação do objeto concreto



Anais do $10^{\circ}$ Congresso Internacional de Design da Informação | CIDI 2021

Proceedings of the $10^{\text {th }}$ Information Design International Conference | CIDI 2021 


\section{Desafios}

Para engajar o aluno e dar exemplo de como trabalhar com o material, foram propostas dinâmicas gamificadas. Estas foram conceitualizadas com o objetivo de instigar o aluno para que ele perceba que detém o conhecimento necessário para completar a tarefa e retomar sua confiança linguística. Assim, foram sugeridas atividades em grupos de 4 ou 5 alunos, que contam pontos e estimulam a competição amigável, usando como base relatos da professora Ana Carolina dos jogos realizados nas aulas da gramaticoteca antes do ER. As dinâmicas podem ser feitas de maneira síncrona ou assíncrona, e o compartilhamento dos resultados é incentivado para promover a interação entre os alunos.

\section{Conclusão}

Os materiais concretos se mostram adaptáveis e de fácil confecção, com o conceito e design simples o suficiente para passar o conteúdo de forma clara e tornar possível sua reprodução em outros tipos de suportes, garantindo a autonomia do aluno em expressar a criatividade e confeccionar o produto da forma que lhe for mais conveniente. As dinâmicas sugeridas apresentam potencial engajador, sem demandar muito tempo dos alunos.

Os próximos passos consistem em aplicar as atividades e os materiais em um contexto real de aulas do ensino público do DF e analisar sua efetividade em engajar os alunos e passar o conteúdo de forma adequada durante o período de ensino remoto.

\section{Agradecimento}

Agradecemos imensamente às professoras Ana Carolina de Castro e Eloisa Pilati por todo o apoio e confiança em todas as etapas do projeto, e por nos mostrar um pouco sobre esse vasto mundo que é a Gramaticoteca.

\section{Referências}

COUTINHO, S. G.; LOPES, M. T. (2011) Design para educação: uma possível contribuição para o ensino fundamental brasileiro. In: BRAGA, M. C. (Org.) O papel social do design gráfico: história, conceitos e atuação profissional. São Paulo: Editora Senac, 201 P. 137-162.

Deterding, S., et al. (2011) Gamification: using game-design elements in non-gaming contexts. In: Proceedings of CHI Extended Abstracts. Nova York: ACM

PILATI, E. (2017) Linguística, Gramática e Aprendizagem Ativa. Campinas: Pontes.

\section{Sobre as autoras}

Ana Cláudia Maynardes, Professora Orientadora, UnB, Brasil <anacm@unb.br> Ana Paula Prado Gomes, Design (cursando), UnB, Brasil <anapaulapradopr@gmail.com> Maria Luiza Capuano Villar, Design (cursando), UnB, Brasil <malucapuano@gmail.com> 